\title{
Healthy interpretation
}

\author{
Moneeza Walji MD MPH, Ken Flegel MDCM MSc
}

- Cite as: CMAJ 2017 October 16;189:E1273. doi: 10.1503/cmaj.171117

$\mathrm{H}$

e entered the emergency department clutching his stomach. Triaged as a nonurgent case, he sat and waited to be seen. Forty-five minutes later, when he looked as if he might vomit and his blood pressure had plummeted, he was moved to a bed and was given intravenous fluids. When members of his family arrived, they asked a staff member why his chest pain had not lessened.

Chest pain?

The working diagnosis for this patient up to this point was gastroesophageal reflux. His first electrocardiogram, performed 75 minutes after his initial symptoms, showed an ST-segment elevation myocardial infarction, and he was rushed to cardiac catheterization. This overweight 65-year-old South Asian man with type II diabetes almost died, for one simple reason: he did not speak English.

Canada has two official languages: English and French. However, many patients in this country speak neither. In 2016, 7.9 million people reported a nonofficial language as their mother tongue. ${ }^{1}$

As in the fictional case described above, many problems arise when patients cannot communicate effectively with health practitioners: misdiagnoses, misunderstandings about diagnoses, miscommunication at discharge - to name a few. Lack of adequate interpretation services also violates patients' rights to confidentiality and informed consent.

Is high-quality medical care in Canada only for those who are fluent in English or French? It should not be. But, because translation services are not standard in Canadian health care facilities, patients who speak other languages may receive substandard care.

Language proficiency has been shown to affect access to care. In 2013, a retrospective study conducted in Sweden compared care given to patients with chest pain who spoke Swedish with care for those who did not. The median time from hospital to percutaneous coronary intervention was 43 minutes longer for patients who did not speak Swedish. ${ }^{2}$ Similarly, a population-based cross-sectional study using data from the Ontario Health Survey completed in 1990 found that women who spoke languages other than English at home were less likely to receive preventive screening, such as mammography and Papanicolaou tests. ${ }^{3}$

Interpretation services can take many forms: telephone interpretation, in-house trained medical interpreters or ad hoc interpreters such as family or support staff. However, all translation services are not equal. A systematic review on the impact of medical interpreter services on the quality of health care found that ad hoc interpreters frequently misinterpreted or omitted questions asked by physicians and were more likely to make errors of clinical consequence compared with trained medical interpreters. ${ }^{4}$

Language strategies for newcomers to Canada have focused traditionally on teaching English or French rather than increasing services available in their own languages. Although this approach may encourage social integration, it cannot ensure official-language health literacy.

Easy-to-use, high-quality interpretation services in the health care sphere will require some creativity. There are two approaches that may be appropriate for Canada: context-specific language services or a standardized program for interpretation services across the country.

The first would ensure that some form of interpretation is available to patients but also would account for differences in local demographics. This would mean providing in-person interpretation in highvolume settings and telephone interpretation where few patients do not speak either official language. The second would be a national telephone interpretation service, available to all centres through a toll-free number.

A 2004 US study estimated that the cost of providing interpretation services that resulted in increased access to preventive care services was US\$279 per person per year. ${ }^{5}$ Research in this area in Canada is lacking. However, it is likely that fit-for-purpose interpretation services would lead to improved access to preventive care services in the Canadian context, which could result in fewer visits to the emergency department. Good translation services would likely result in more successful discharges from hospital and improved therapeutic alliance with physicians in the outpatient setting.

Inherent in Canadian values is universal access to health care. But access means more than the ability to walk through the doors of a hospital. It means access to appropriate care. All patients, no matter which language they speak, deserve to receive the best medical care available. That will only happen when all patients can be understood.

\section{References}

1. An increasingly diverse linguistic profile: Corrected data from the 2016 Census. Ottawa: Statistics Canada; 2017. Available: www.statcan.gc.ca/daily-quotidien /170817/dq170817a-eng.htm (accessed 2017 Sept. 10).

2. Santos M, Ravn-Fischer A, Karlsson T, et al. Is early treatment of acute chest pain provided sooner to patients who speak the national language? Int J Qual Health Care 2013;25:582-9.

3. Woloshin S, Schwartz LM, Katz SJ, et al. Is language a barrier to the use of preventive services? J Gen Intern Med 1997;12:472-7.

4. Flores G. The impact of medical interpreter services on the quality of health care: a systematic review. Med Care Res Rev 2005;62:255-99.

5. Jacobs EA, Shepard DS, Suaya JA, et al. Overcoming language barriers in health care: costs and benefits of interpreter services. Am J Public Health 2004;94:866-9.

Competing interests: See www.cmaj.ca/site/misc/cmaj_staff.xhtml

Affiliations: See www.cmaj.ca/site/misc/cmaj_staff.xhtml

Correspondence to: CMAJ editor,pubs@cmaj.ca 